\title{
RENDIMENTOFORRAGEIRO E VALOR NUTRITIVO DE CLONES DE PENNISETUM SOB CORTE, NA ZONA DA MATA SECA*
}

\author{
FORAGE YIELD AND NUTRITIVE VALUE IN PENNISETUM CLONES HARVESTED IN \\ THE FOREST ZONE
}

\author{
Silva, M.A ${ }^{1}$, Lira, M.A. ${ }^{2}$, Santos, M.V.F. ${ }^{3}$, Dubeux Junior, J.C.B. ${ }^{3}$, Freitas, E.V. de $^{2}$ e \\ Araújo, G.G.L. ${ }^{4}$
}

\begin{abstract}
1Universidade Federal Rural de Pernambuco - UFRPE. Brasil. monica.zte@gmail.com.br
2IPA. Recife. Brasil. mlira@terra.com.br

3UFRPE/PPGZ. Recife. Brasil. mercia@dz.ufrpe.br; dubeux@dz.ufrpe.br

${ }^{4}$ EMBRAPA Semi-Árido. Petrolina. Brasil. guerman@embrapa.br
\end{abstract}

\section{PalaVRas chave adicionais}

Colmo. Digestibilidade. Herdabilidade. Lâminas foliares. Proteína bruta.

\section{RESUMO}

Objetivou com este trabalho verificar a produção e valor nutritivo de cinco genótipos de Pennisetum (IRI-381, Venezuela, Elefante B, HV241 e Hexaplóide) sob corte na Zona da Mata Seca de Pernambuco. As amostras foram obtidas de uma área útil de $2,0 \mathrm{~m}^{2}$, num delineamento em blocos casualizados com 6 repetições. Após o corte de uniformização, efetuaram-se quatro cortes a intervalos de 60 dias. Foi tomada uma amostra de três perfilhos de cada parcela. Foram avaliados os percentuais de matéria seca (MS), proteína bruta (PB), fibra em detergente neutro (FDN), fibra em detergente ácido (FDA), extrato etéreo ( $E E)$, matéria mineral $(M M)$, digestibilidade in vitro da matéria seca (DIVMS) carboidratos totais (CHOT) e carboidratos não fibrosos (CNF). Os genótipos avaliados apresentaram rendimento médio de MS de lâminas foliares de 1,7 t/ha/corte e de colmos de $2,1 \mathrm{t} / \mathrm{ha} / \mathrm{corte}$, não havendo diferença entre clones $(p>0,05)$. Nas lâminas foliares e nos colmos, respectivamente, observouse 21,1 a $15,1 \%$ para MS; 9,1 a 5,3\% para PB; 73,2 a $77,7 \%$ para FDN; 40,3 a $47,4 \%$ para FDA; 9,6 a $11,6 \%$ para $\mathrm{MM} ; 1,9$ a $0,7 \%$ para EE; 56,2 a $56,3 \%$ para DIVMS; 79,3 a $82,4 \%$ para CHOT e 11,4 a $9,7 \%$ para CNF. Os clones apresentaram de média a alta herdabilidade e rendimento forrageiro e

*Projeto financiado pelo CNPq e PROMATA, realizado pelo acordo IPA-UFRPE.

\section{AdditionAl KEYWORDS}

Stem. Digestibility. Heritability. Leaf blade. Crude protein.

valor nutritivo semelhantes, quando manejados aos 60 dias de idade nas condiçoes da zona da mata seca de Pernambuco.

\section{SUMMARY}

The objective of this work was to verify the MS production and nutritive value of five clones of Pennisetum. The samples were taken from an utile area of $2,0 \mathrm{~m}^{2}$ in each plot. After clipping the forage to standarize, four cuts were performed with 60d intervals. In each plot, three tillers were ovendried and grinded for laboratory analysis. The following response variables were determined: dry matter concentration (MS), crude protein (PB), neutral detergent fiber (FDN), acid detergent fiber (FDA), ether extract (EE), mineral matter (MM), in vitro dry matter digestibility (DIVMS), total carbohydrates (CHOT), and non-fibrous carbohydrates (CNF). The evaluated genotypes presented average MS yield of 1.7 and $2.1 \mathrm{t} / \mathrm{ha} /$ cut, for leaf blade and stem, respectively. Average nutritive value was 21.1 and $15.1 \%$ for MS; 9.1 and $5.3 \%$ for $\mathrm{PB} ; 73.2$ and $77.7 \%$ for FDN; 40.3 and $47.4 \%$ for FDA; 9.6 and $11.6 \%$ for MM; 1.9 and $0.7 \%$ for EE; 56.2 and $56.3 \%$ for DIVMS; 79.3 and $82.4 \%$ for $\mathrm{CHOT}$; and 11.4 and $9.7 \%$ for $\mathrm{CNF}$, in leaf blades and stem, respectively. The clones presented medium to high heritability, similar biomass production and nutritive value, when 
SILVA, LIRA, SANTOS, DUBEUX JUNIOR, FREITAS E ARAÚJO

harvested at 60 days of regrowth in the conditions of the forest zone of Pernambuco.

\section{INTRODUÇÃO}

O Pennisetum purpureum Schum é uma gramínea de origem tropical que se destaca por sua adaptação a uma grande diversidade de ambientes e a diferentes condições de clima e solo, caracterizando-se por seu alto potencial de produção e qualidade nutritiva (Kollet et al., 2006). Este potencial produtivo, associado às outras características forrageiras favoráveis, tais como boa qualidade, tem estimulado não só o cultivo dessa espécie como também o seu melhoramento genético, visando o desenvolvimento de cultivares para utilização sob pastejo e para capineiras (Sobrinho et al., 2005).

Está gramínea tem sido bastante estudada com o intuito de selecionar genótipos superiores aos atualmente cultivados, adaptados a cada realidade ambiental do país (Mello et al., 2006). Atualmente desenvolvese um programa de melhoramento do capim elefante pelo Institudo Agronomico de Pernambuco em parceria com a Universidade Federal Rural de Pernambuco, cujas fases são: Fase I - Os genótipos são avaliados sob corte em pequenas parcelas para aspectos de produção de forragem e é dada grande ênfase na avaliação de ataques de pragas e doenças. Fase II - Os genótipos selecionados na fase anterior são avaliados com a presença do animal, em parcelas maiores. Fase III - Os genótipos selecionados na fase anterior são avaliados sob pastejo onde a produção por animal e por área é mensurada.

O Pennisetum apresentam elevado potencial de produção, firmando-se como uma espécie de extrema importância para manutenção de altos níveis de produtividade dentro da produção animal. Entretanto, são escassos relatos a respeito da qualidade nutricional desses germoplasmas melhorados. Sabe-se, que ocorre uma redução no valor nutritivo com o aumento da idade das plantas, resultando num incremento nos teores de matéria seca, e compo- nentes fibrosos, ao mesmo tempo em que se reduzem os teores de proteína bruta e a digestibilidade (Pereira et al., 2000). Devese salientar que, o valor nutritivo da forragem reflete seu potencial em termos de qualidade, tornando-se imprescindível elevar-se a produtividade animal.

No processo de seleção, a qualidade da forragem irá depender de vários fatores, como idade da planta, condições climáticas entre outros, por ser um caráter complexo resultante da expressão e associação de diferentes componentes (Carvalho et al., 2002). Após o conhecimento da composição química, a obtenção de estimativas dos valores de digestibilidade é reconhecidamente essencial para determinar o valor nutritivo dos alimentos (Valadares Filho et al., 2000).

A partir da clonagem de progênies colhidas de sementes, pode-se avaliar e selecionar os clones resultantes em diversas condições edafoclimáticas, selecionando alta produtividade e valor nutritivo, obtendo-se novas cultivares. Desta forma, a herdabilidade é um parâmetro muito importante para predizer caracteres que possam influenciar geneticamente a composição nutricional dessas gramíneas. Segundo Mello et al. (2006a), este parâmetro genético pode expressar a variação genética em relação à variação fenotípica. A estimativa dessa variável é importante para expressar a confiança do valor fenotípico como guia para predizer o valor genético (Lira et al., 2004).

Objetivou-se com este trabalho determinar a produção, valor nutritivo e a herdabilidade de características de cinco clones de Pennisetum sob corte na zona da mata seca de Pernambuco.

\section{MATERIAL E MÉTODOS}

O trabalho foi realizado na Estação Experimental de Itambé, pertencente ao Instituto Agronômico de Pernambuco (IPA), localizado em Itambé, zona da mata seca de Pernambuco. A Estação apresenta como 


\section{RENDIMENTO E VALOR NUTRITIVO DE CLONES DE PENNISETUM SOB CORTE}

coordenadas geográficas $07^{\circ} 25^{\prime} 00^{\prime \prime} \mathrm{S}, 35^{\circ} 06^{\prime}$ 00" SWGr. e altitude de $190 \mathrm{~m}$. A precipitação pluvial anual é em torno de $1300 \mathrm{~mm}$ com $70 \%$ deste total ocorrendo nos meses de março a julho, e a temperatura média anual é de $25,1^{\circ} \mathrm{C}$. O clima é classificado como do tipo sub-úmido megatérmico (IPA, 1994; EMBRAPA, 1999).

Foram avaliados cinco genótipos de Pennisetum, dos quais três foram de capim elefante(IRI-381, Venezuela e Elefante B) e dois foram híbridos do capim elefante com milheto (HV-241 e Hexaplóide). Estes genótipos foram selecionados da Fase I (Mello et al., 2002) e Fase II (Freitas et al., 2004) do Programa de Melhoramento Genético do capim elefante realizado pelo IPA/ UFRPE, o qual segue metodologia proposta por Valle e Souza (1995).

O experimento foi realizado em uma área de exclusão contida numa área de pastagem com 5 ha, dividida em 6 piquetes. Os piquetes foram subdivididos em cinco áreas de aproximadamente $833 \mathrm{~m}^{2}$. Cada subdivisão foi ocupada por um genótipo de Pennisetum sp. A área de exclusão de cada subdivisão correspondeu a $24 \mathrm{~m}^{2}(4 \times 6 \mathrm{~m})$, sendo considerada como área útil $2 \mathrm{~m}^{2}$, para as avaliações. O delineamento foi em blocos casualizados, com repetições.

A pastagem foi implantada no início do segundo semestre de 2003, sendo manejada sob pastejo. A área de exclusão para realização do experimento sob corte foi cercada no segundo semestre de 2005, sendo realizada adubação de cobertura com 60 kg.ha ${ }^{-1}$ de $\mathrm{K}_{2} \mathrm{O} ; 50 \mathrm{~kg} \cdot \mathrm{ha}^{-1}$ de N e $100 \mathrm{~kg} \cdot \mathrm{ha}^{-1}$ de $\mathrm{P}_{2} \mathrm{O}_{5}$. De acordo com o perfil de 0 a $20 \mathrm{~cm}$, o solo da área experimental foi classificado como franco-arenoso (18\% de argila), apresentando densidade aparente de $1,1 \mathrm{~g}$ $\mathrm{cm}^{-3}$. Com relação às características químicas, considerando o mesmo perfil ( 0 a 20 $\mathrm{cm})$, a análise realizada apresentou o seguinte resultado: $\mathrm{pH}$ (em água) $=5,5 ; \mathrm{P}=5 \mathrm{ppm}$ (Mehlich-I); matéria orgânica $=2,8 \% ; \mathrm{Ca}^{++}=$ $3,3(100 \mathrm{~cm})^{-3}$ de solo; $\mathrm{Mg}^{++}=1,4(100 \mathrm{~cm})^{-3}$ de solo; $\mathrm{Na}^{++}=0,05(100 \mathrm{~cm})^{-3}$ de solo; $\mathrm{K}^{+}=$
$0,2(100 \mathrm{~cm})^{-3}$ de solo; $\mathrm{Al}^{+3}=0,2(100 \mathrm{~cm})^{-3} \mathrm{de}$ solo; $\mathrm{H}^{+}=6,5(100 \mathrm{~cm})^{-3}$ de solo; $\mathrm{S}=5,0(100$ $\mathrm{cm})^{-3}$ de solo; $\mathrm{CTC}=11,8(100 \mathrm{~cm})^{-3}$ de solo; $\mathrm{V}=44 \%, \mathrm{~m}=3,8 \%$.

O período experimental foi iniciado com corte de uniformização rente ao solo (17/08/ $2005)$, e a cada 60 dias foram realizadas as avaliações em um quadrado de $1 \mathrm{~m}^{2}$, dentro de uma área útil de $2 \mathrm{~m}^{2}$, nas referidas datas 17/10/2005 (21,0 mm), 17/12/05 (11 mm), 17/ 04/2006(177,8 mm) e 17/06/2006(192,0 mm), totalizando 4 cortes ao final do período experimental. Os valorer entre parentese referem-se as precipitações pluviométricas mensais. Em 17/02/2006 (33,4 mm) não houve avaliação devido à falta de crescimento do material, em conseqüência da época seca. Entretanto, houve o corte nas plantas existentes para que a colheita de 17/04 representasse a mesma idade das demais.

Foram retiradas amostras da planta inteira em $1 \mathrm{~m}$ linear/parcela, que foram separadas em lâminas foliares e colmos mais bainhas. A produção de matéria seca de lâminas foliares $(\mathrm{t} / \mathrm{ha})$ foi determinada considerando-se o peso médio das lâminas foliares existentes dentro do quadrado, multiplicado pelo seu teor de matéria seca e extrapolado para um hectare; procedimento semelhante foi realizado com o colmo. Após a pesagem foram retirados 3 perfilhos representativos para determinação dos teores de matéria seca (MS), proteína bruta $(\mathrm{PB})$, fibra em detergente neutro (FDN), fibra em detergente ácido (FDA), estrato etéreo (EE) e matéria mineral (MM) segundo Silva e Queiroz (2002); carboidratos totais (CT) e carboidratos não fibrosos (CNF) segundo Sniffen et al. (1992); digestibilidade in vitro da matéria seca (DIVMS) segundo Tilley e Terry (1963). As análises de DIVMS foram realizadas no Laboratório de Análises Químicas da Embrapa Semi-Árido. As demais análises foram feitas no Laboratório de Nutrição Animal do Departamento de Zootecnia da UFRPE.

Foi realizada análise de variância entre os cinco cortes estudados. Considerando- 


\section{SILVA, LIRA, SANTOS, DUBEUX JUNIOR, FREITAS E ARAÚJO}

se que não houve interação significativa entre os tratamentos e os cortes, utilizou-se a média para os quatro cortes.

A herdabilidade foi estimada através da formula $\mathrm{h}^{2}=\mathrm{QMt} /(\mathrm{QMt}+\mathrm{QMr})$, conforme metodologia descrita por Shimoya et al. (2002). Para interpretação dos valores das herdabilidade no sentido amplo $\left(\mathrm{h}^{2}\right)$ usouse como critério a significância das médias.

Para realização da analise de variância foi utilizado o procedimento GLM (General Linear Models) do SAS (Cruz, 2001). As médias dos genótipos foram comparadas pelo teste de Tukey, ao nível de 5\%.

\section{RESULTADOSEDISCUSSÃO}

Não houve diferença significativa $(p>0,05)$ para a produção de matéria seca de lâminas foliares e colmos entre os genotípos estudados (tabela I). Lira et al. (1999), trabalhando com produção de matéria seca em cultivares de capim elefante, não observaram diferenças significativas entre genótipos, que apresentaram médias de 2,2

Tabela I. Produção de matéria (t/ha) seca em lâminas foliares e colmos de clones de Pennisetum sob corte em Itambé-PE. (Dry matter yield ( $t / h a)$ of leaf blades and stems of Pennisetum sp. clones under cut; Itambé-PE).

\begin{tabular}{lcc}
\hline Clones & Lâmina foliar & Colmo \\
\hline IRI381 & $1,8^{\mathrm{a}}$ & $3,4^{\mathrm{a}}$ \\
Venezuela & $1,9^{\mathrm{a}}$ & $2,0^{\mathrm{a}}$ \\
Hexaplóide & $1,4^{\mathrm{a}}$ & $1,5^{\mathrm{a}}$ \\
HV 241 & $1,5^{\mathrm{a}}$ & $1,5^{\mathrm{a}}$ \\
Elefante B & $1,9^{\mathrm{a}}$ & $1,9^{\mathrm{a}}$ \\
Média & 1,7 & 2,1 \\
Desvio padrão & 0,6 & 1,3 \\
Valor maximo & 3,4 & 8,0 \\
Valor mínimo & 0,6 & 0,3 \\
CV (\%) & 40,9 & 54,7 \\
$\mathrm{~h}^{2}$ & 0,34 & 0,73 \\
\hline
\end{tabular}

Médias ( 5 repetições) seguidas na mesma letra na coluna não diferem pelo teste de Tukey $(p>0,05)$.

Archivos de zootecnia vol. 60, núm. 229, p. 66. e 1,7 t/ha para os genótipos Venezuela e Elefante B, respectivamente.

A produção de matéria seca de lâminas foliares apresentou valor médio de 1,7 t/ha/ corte, enquanto que de colmos esse valor foi de 2,1 t/ha/corte. A média encontrada para lâminas foliares representou em torno de $44,7 \%$ da produção de MS total. Esses resultados são importantes, pois a produção de MS em lâminas foliares constitui um dos principais aspectos a serem considerados na escolha de genótipos superiores (Mello et al., 2002), e por ser a fração da forragem que se obtém mais alto valor nutritivo.

Os valores encontrados neste trabalho foram inferiores aos observados por Mello et al. (2002) que observaram valores de MS total de 10,2 t/ha/ na estação chuvosa e 5,0 t/ha na estação seca. Freitas et al. (2004), avaliando taxa de acúmulo de lâminas foliares acima de $40 \mathrm{~cm}$ em capim elefante sob pastejo, não observaram diferenças significativas $(p>0,05)$ entre os genotípos, com média de 3,3;3,0 e 2,5 t MS/ha/35 dias para o IRI 381, Venezuela e Hexaplóide, respectivamente. Os resultados encontrados no presente trabalho foram semelhantes aos de Oliveira et al. (2007), que observaram produção média de $1,7 \mathrm{t} /$ ha de MS em capim elefante sob pastejo no periodo chuvoso do ano e aos encontrados por Santos et al. (1994), avaliando genótipos de capim elefante no Agreste de Pernambuco, destacando-se os materiais Elefante B, IRI 381 e Venezuela com produtividade entre 1,6; 1,5 e 1,5 t/ha/60 dias.

Apesar do alto coeficiente de variação, que em experimentos com avaliação da MS se tornam comum quando realizados sob corte, é importante salientar que este coeficiente neste tipo de experimento representa além do grau de precisão, a variabilidade fenotípica entre os genotípos estudados. Segundo Mello et al. (2002), valores de CV relativamente altos encontrados para caracteres como produção de MS e de lâmina foliar, demonstram maior potencial de seleção para o caractere em estudo, enquanto baixos 


\section{RENDIMENTO E VALOR NUTRITIVO DE CLONES DE PENNISETUM SOB CORTE}

valores de CV indicariam menor variabilidade entre os genotípos e, por tanto, mais baixa possibilidade de seleção. Entretanto, coeficientes de variação altos, indicam que o material está susceptível a variações ambientais não controladas, dificultando a seleção de caracteres.

A análise dos teores de MS de laminas foliares e colmos não mostrou diferença entre os tratamentos $(p>0,05)$, tendo os genotípos apresentados em média teores de 22,1 e $15,5 \%$, respectivamente (tabela II). Os resultados de matéria seca para lâminas foliares foram superiores aos encontrados por Freitas et al. (2004), ao observarem em 16 clones, média de $17,3 \%$ de matéria seca, não diferindo entre os genótipos.
Segundo Soares et al. (2004), o teor de MS é importante, pois influencia o consumo da forragem. Este autores observaram que aos 30 dias de idade, o teor de MS foi baixo, inferindo na redução do consumo, em decorrência do elevado teor de umidade. Verité e Journet (1970) citam valores críticos abaixo de $18 \%$ de MS em forragem. Diante destes resultados, os teores de MS da média ponderada de folhas e colmos apresentaram próximos $(19,0 \%)$ a estes valores. Os valores encontrados para os teores de MS aos 60 dias de idade, em lâminas foliares não foram diferentes estatisticamente dos teores de MS de colmos (tabela III).

A análise de dados referentes aos teores de PB de lâminas foliares e colmos (tabela

Tabela II. Teores médios de matéria seca (MS), proteina bruta (PB), fibra em detergente neutro (FDN), fibra em detergente ácido (FDA), digestibilidade in vitro (DIVMS), matéria mineral (MM), extrato etéreo (EE), carboidratos totais (CT) e carboidratos não fibrosos $(C N F)$ em lâminas foliares e colmos de clones de Pennisetum. (Dry matter concentration (MS), crude protein (PB), neutral detergent fiber (FDN), acid detergent fiber (FDA), in vitro dry matter digestibility (DIVMS), mineral matter (MM), ether extract (EE), total carbohydrates (CT), and non-fibrous carbohydrates (CNF) in leaf blades and stems of Pennisetum clones).

\begin{tabular}{lccccccccc}
\hline & MS & PB & FDN & FDA & DIVMS & MM & EE & CT & CNF \\
\hline Lâminas foliares (\%) & & & & & & & & & \\
IRI381 & $20,0^{\mathrm{a}}$ & $9,6^{\mathrm{a}}$ & $72,4^{\mathrm{a}}$ & $38,8^{\mathrm{ab}}$ & $58,2^{\mathrm{a}}$ & $10,1^{\mathrm{a}}$ & $1,9^{\mathrm{a}}$ & $78,4^{\mathrm{b}}$ & $11,7^{\mathrm{a}}$ \\
Venezuela & $23,1^{\mathrm{a}}$ & $8,1^{\mathrm{a}}$ & $73,1^{\mathrm{a}}$ & $40,1^{\mathrm{ab}}$ & $56,1^{\mathrm{a}}$ & $8,6^{\mathrm{a}}$ & $1,9^{\mathrm{a}}$ & $81,4^{\mathrm{a}}$ & $11,9^{\mathrm{a}}$ \\
Hexaplóide & $19,1^{\mathrm{a}}$ & $9,4^{\mathrm{a}}$ & $74,5^{\mathrm{a}}$ & $42,1^{\mathrm{a}}$ & $55,1^{\mathrm{a}}$ & $9,5^{\mathrm{a}}$ & $1,9^{\mathrm{a}}$ & $79,2^{\mathrm{ab}}$ & $15,7^{\mathrm{a}}$ \\
HV 241 & $23,0^{\mathrm{a}}$ & $9,1^{\mathrm{a}}$ & $72,7^{\mathrm{a}}$ & $32,7^{\mathrm{b}}$ & $55,4^{\mathrm{a}}$ & $9,1^{\mathrm{a}}$ & $1,7^{\mathrm{a}}$ & $77,2^{\mathrm{b}}$ & $18,8^{\mathrm{a}}$ \\
Elefante B & $25,3^{\mathrm{a}}$ & $8,9^{\mathrm{a}}$ & $73,6^{\mathrm{a}}$ & $38,7^{\mathrm{ab}}$ & $58,7^{\mathrm{a}}$ & $9,7^{\mathrm{a}}$ & $1,8^{\mathrm{a}}$ & $79,6^{\mathrm{ab}}$ & $10,7^{\mathrm{a}}$ \\
Média & 22,1 & 9,0 & 73,2 & 38,5 & 56,7 & 9,4 & 1,8 & 79,2 & 13,8 \\
CV (\%) & 15,3 & 8,6 & 2,7 & 6,8 & 4,5 & 9,7 & 3,9 & 1,3 & 48,0 \\
h$^{2}$ & 0,62 & 0,64 & 0,35 & 0,84 & 0,56 & 0,54 & 0,57 & 0,87 & 0,43 \\
& & & & & & & & & \\
Colmos (\%) & & & & & & & & & \\
IRI381 & $19,8^{\mathrm{a}}$ & $4,8^{\mathrm{a}}$ & $81,0^{\mathrm{a}}$ & $50,9^{\mathrm{a}}$ & $54,7^{\mathrm{a}}$ & $11,6^{\mathrm{a}}$ & $0,6^{\mathrm{a}}$ & $82,5^{\mathrm{a}}$ & $6,3^{\mathrm{a}}$ \\
Venezuela & $14,2^{\mathrm{a}}$ & $5,2^{\mathrm{a}}$ & $76,9^{\mathrm{a}}$ & $45,4^{\mathrm{a}}$ & $56,7^{\mathrm{a}}$ & $10,3^{\mathrm{a}}$ & $0,7^{\mathrm{a}}$ & $83,7^{\mathrm{a}}$ & $9,8^{\mathrm{a}}$ \\
Hexaplóide & $15,5^{\mathrm{a}}$ & $6,1^{\mathrm{a}}$ & $77,2^{\mathrm{a}}$ & $46,4^{\mathrm{a}}$ & $55,7^{\mathrm{a}}$ & $11,2^{\mathrm{a}}$ & $0,8^{\mathrm{a}}$ & $82,1^{\mathrm{a}}$ & $6,5^{\mathrm{a}}$ \\
HV 241 & $13,7^{\mathrm{a}}$ & $5,1^{\mathrm{a}}$ & $77,7^{\mathrm{a}}$ & $46,4^{\mathrm{a}}$ & $53,9^{\mathrm{a}}$ & $13,5^{\mathrm{a}}$ & $0,7^{\mathrm{a}}$ & $80,9^{\mathrm{a}}$ & $9,2^{\mathrm{a}}$ \\
Elefante B & $14,5^{\mathrm{a}}$ & $4,8^{\mathrm{a}}$ & $77,2^{\mathrm{a}}$ & $47,7^{\mathrm{a}}$ & $56,9^{\mathrm{a}}$ & $11,8^{\mathrm{a}}$ & $0,8^{\mathrm{a}}$ & $82,5^{\mathrm{a}}$ & $7,7^{\mathrm{a}}$ \\
Média & 15,5 & 5,2 & 78,0 & 47,4 & 55,6 & 11,7 & 0,7 & 82,3 & $7,9^{2}$ \\
CV (\%) & 21,1 & 10,2 & 3,7 & 4,1 & 6,9 & 11,2 & 19,5 & 1,5 & 19,8 \\
h $^{2}$ & 0,63 & 0,76 & 0,51 & 0,79 & 0,25 & 0,70 & 0,54 & 0,68 & 0,75 \\
\hline
\end{tabular}

Médias (4 repetições) seguidas na mesma letra na coluna não diferem pelo teste de Tukey $(p>0,05)$. 


\section{SILVA, LIRA, SANTOS, DUBEUX JUNIOR, FREITAS E ARAÚJO}

II), não revelou diferença significativa $(\mathrm{p}>0,05)$ para os genotípos. A média ponderada do teor de $\mathrm{PB}$ para todos os componentes da forragem foi de $7,1 \%$, sendo superior à média obtida por Lacerda et al. (2004) com $5,7 \%$ e Mello et al. (2006) com 5,02\%. Por outro lado, foram inferiores aos encontrados por Queiroz Filho et al. (2000) que encontraram teores de $8,6 \%$ de PB, aos 60 dias de idade, para o cultivar Roxo (média anual). Esses resultados corroboram a afirmação de Silva et al. (2002) de que a composição química de genótipos de capimelefante parece ser extremamente influenciada por fatores como intervalos de corte, idade biológica da planta e ambiente.

Todos os valores de PB para lâminas foliares encontrados neste experimento estão acima dos descritos por Minson (1984), que preconizou a necessidade de ingestão de forragem com o mínimo de 6 a $8 \%$ de $\mathrm{PB}$ na MS para manutenção de um consumo voluntário adequado. Previsivelmente, os teores de PB da lâmina foliar foram diferentes dos teores encontrados no colmo (tabela III), o que indica que a folha

Tabela III. Esquema da analise de variância referente às variáveis bromatologicas das plantas de Pennisetum sp. (Outline of the it analyzes of variance regarding the variables sprouting of the plants of Pennisetum sp.).

\begin{tabular}{lccccc}
\hline \multicolumn{5}{c}{ significância } \\
& E & PP & IExPP & Média & CV (\%) \\
& & & & & \\
MS & ns & ns & ns & 18,8 & 17,7 \\
PB & ns & $*$ & ns & 7,1 & 9,4 \\
FDN & ns & $*$ & ns & 75,6 & 3,3 \\
FDA & ns & $* *$ & $* *$ & 42,9 & 5,3 \\
EE & ns & ns & ns & 10,5 & 10,7 \\
MM & ns & $* *$ & ns & 1,3 & 12,3 \\
DIVMS & ns & ns & ns & 56,2 & 5,8 \\
CT & $*$ & ns & ns & 80,7 & 1,4 \\
CNF & ns & $* *$ & ns & 10.8 & 60,3 \\
& & & & & \\
\hline
\end{tabular}

$\mathrm{E}=$ Espécie; $\mathrm{PP}=\mathrm{Partes}$ da planta (colmo e folha); $\mathrm{I}=$ Interação; ${ }^{*} p<0,05 ;{ }^{* *} p<0,01$.

Archivos de zootecnia vol. 60, núm. 229, p. 68. possui uma qualidade superior em relação ao colmo, para os referidos genotípos.

Em relação aos teores de FDN de lâminas foliares e de colmos, não foi observada diferença significativa para os genotípos estudados entre as partes da planta, porém entre os colmos e as folhas foi observada diferença significativa. Concordando com estes resultados de Barreto et al. (2001) que não observaram diferenças $(\mathrm{p}>0,05)$ entre os clones de capim elefante para teores de FDN.

Os teores médios de FDN em lâminas foliares foram de 73,2\% e em colmos de $78,0 \%$ (tabela II). Estes valores foram superiores aos encontrados por diversos autores (Freitas et al., 2004; Lopes et al., 2005; Mello et al., 2006), sendo considerados altos, pois segundo Reis et al. (2000), teores de fibra em detergente neutro acima de $60 \%$ podem alterar a digestibilidade da MS. Desta forma, os teores de FDN encontrados no presente trabalho podem ter contribuído para a diminuição da digestibilidade da MS, uma vez que, segundo Van Soest (1965), o teor de FDN é inversamente correlacionado com a digestibilidade da MS. O FDN alto pode ter sido resultado das amostras compostas, onde estava inserido o período seco do ano.

Com relação aos teores de FDA em lâminas foliares, foram observadas diferenças $(p<0,05)$ entre os clones, com maiores teores de FDA para os genotípos Hexaplóide e Venezuela, com respectivos valores de 42,8 e 40,1\%. Os menores valores de FDA foram registrados para os clones IRI $381 \mathrm{e}$ HV 241, respectivamente de 38,7 e $38,1 \%$ (tabela II). Os teores de FDA em colmos não apresentaram diferença significativa entre os genotípos estudados. Observou-se que entre a lâmina foliar e o colmo houve diferença significativa, indicando que a folha apresentou média inferior ao colmo. Entretanto, vale ressaltar que o hibrido HV241 foi um dos genótipos que apresentou o menor valor de FDA, possivelmente devido ao seu cruzamento ser entre um capim elefante e 


\section{RENDIMENTO E VALOR NUTRITIVO DE CLONES DE PENNISETUM SOB CORTE}

milheto, onde o segundo é considerado de boa qualidade, sendo essa característica passada a sua progênie.

Os valores deste trabalho são inferiores aos encontrados por Mello et al. (2006), que obtiveram teor médio de FDA de $42,8 \%$ em genotípos de capim elefante, e superiores aos encontrados por Lopes et al. (2005), que obtiveram teor médio de FDA de $33,0 \%$ em lâminas foliares de capim elefante sob condições irrigadas e de sequeiro. Andrade et al. (2003) observaram que forragens com teores de FDA em torno de 30\% não comprometem o valor nutritivo da forragem; os valores deste estudo $(39,9 \%)$ foram superiores a esta média, possivelmente comprometendo o valor nutritivo. $\mathrm{O}$ aumento da FDA provavelmente ocasiona a diminuição da digestibilidade da MS em lâminas foliares aos 60 dias de idade (Pinto et al., 1999; Pereira et al., 2000; Pompeu et al., 2006).

Não foram observadas diferenças significativas $(\mathrm{p}<0,05)$ nos teores de DIVMS de lâminas foliares e colmos, entre os genotípos de Pennisetum ((tabelas II e III), possivelmente essas diferenças não se apresentaram devido a este material ter sido avaliado na época seca do ano, influenciando na falta de alongamento do colmo. Foram obtidos valores médios de 56,7 e 55,6\% para lâminas foliares e colmos, respectivamente. Estes valores são inferiores aos encontrados por Missio et al. (2006), que obtiveram 82,9\% em lâminas foliares de capim elefante, porém com idade de 21 dias, o que infere na digestibilidade diminuir com o avanço da idade. Valores semelhantes aos deste trabalho foram observados por outros autores (Deschamps e Brito 2001; Soares et al., 2004 ), que encontraram médias de $52 \%$ aos 60 dias de idade.

Os teores de digestibilidade in vitro da MS nas lâminas foliares dos genotípos estudados foram considerados baixos. Isto possivelmente ocorreu devido aos teores de FDN terem sido superiores a $60 \%$, desta forma influenciando na diminuição da digestibilidade. Segundo Rodrigues et al. (2004), a susceptibilidade à degradação ruminal da porção fibrosa varia com a idade ou nível de maturação da forrageira. Assim, à medida que a planta se desenvolve, ocorre redução do teor protéico e aumento do teor de fibra, associado à elevação no teor de lignina. A lignina forma uma barreira que impede a aderência microbiana e a hidrólise enzimática da celulose e hemicelulose, indisponibilizando os carboidratos estruturais potencialmente degradáveis e diminuindo a digestibilidade da MS. Porém, Nussio et al. (1998) afirmam que a digestibilidade da parede celular de gramíneas não se limita apenas pela composição química, mas pela percentagem de participação de determinados tecidos na haste da planta (parênquima), bem como da arquitetura da célula. Segundo os mesmos autores, a fibra representa a fração do alimento de digestão lenta ou indigestível e, dependendo de sua concentração, limita o consumo de MS e energia. Sua digestibilidade vai depender de características químicas e físicas, sendo as químicas relacionadas à composição da lignina, e as físicas ao poder tampão ou densidade (Nussio et al., 2006).

A porcentagem de MM na lâmina foliar oscilou de 8,6 a 10,1\%. Quanto à porcentagem de MM no colmo, esta oscilou de 10,3 a $13,5 \%$, para os genotípos Venezuela e HV 241 , respectivamente, sendo a média geral de $10,5 \%$. É importante observar que provavelmente pelo fato das amostras para análise terem sido coletadas separadamente em lâmina foliar e colmo, isto não influenciou o nivel de significancia entre as lâminas foliares e os colmos. Os valores encontrados neste trabalho foram superiores aos encontrados por Santos et al. (1998), Oliveira (1999) e Santos et al. (2001) e inferiores aos encontrados por Figueiredo et al. (2004) que observaram teor de 11,8\%, em plantas de capim elefante. Entretanto, foram semelhantes aos encontrados por Silva (2001) que apresentou média de 10,7\% para planta inteira de capim elefante. 
Observou-se que a MM não apresentou significância entre as espécies $(\mathrm{p}>0,05)$ para lâminas foliares e para colmos (tabela II), apresentando um coeficiente de variação considerado baixo, o que infere na possibilidade de baixa variação genética e ambiental, nos genotípos avaliados. Diante desses resultados, reconhecidamente o teor de MM nas forragens depende de vários fatores, incluindo a espécie e estádio de maturação. Assim, a baixa variabilidade entre os genotípos pode ser decorrente dos mesmos apresentarem a mesma idade e serem provenientes da mesma espécie forrageira. Considerando esses fatores, fica evidenciada a importância da avaliação da composição mineral na forragem, pois segundo Van Soest (1994), a deficiência dela pode provocar redução no desempenho animal aliados a aumentos em problemas sanitários.

Com relação aos teores de $\mathrm{EE}$, não foi observada significância $(\mathrm{p}>0,05)$ entre os genotípos avaliados, tanto para lâminas foliares com teor médio de $1,8 \%$ (tabela II), como para colmos com teor de $0,7 \%$ (tabela III). Observou-se que o EE é estável nos colmos, não sofrendo variações consideráveis. Os resultados deste trabalho foram semelhantes aos apresentados por Figueiredo et al. (2004) que observaram teores de $2,8 \%$ de EE em plantas de capim elefante em estágio vegetativo.

Os baixos valores de EE apresentado neste trabalho são importantes, pois segundo Reis et al. (2000), o EE contribui para a diminuição da digestibilidade da matéria seca. Van Soest (1994) considera para ruminantes níveis máximos de $7 \%$ de EE na dieta total para que não haja comprometimento da digestibilidade e consumo de nutriente. Desta forma, os resultados obtidos neste trabalho, não comprometeram digestibilidade.

Maiores $(p<0,05)$ teores de carboidratos totais foram constatados nos genotípos Venezuela e Hexaplóide, com valores de 81,4 e $79,7 \%$, respectivamente (tabela II). Os menores $(p<0,05)$ teores médios de carboi- dratos totais de lâminas foliares foram observados para os genotípos IRI 381 e HV 241 , com valores de 78,3 e 77,5\%, respectivamente. Em relação aos carboidratos totais para colmos, não foram observadas diferenças significativas entre os genotípos estudados. Apesar dos clones apresentarem significância, quando se avalia as variáveis em relação às partes da planta, essas não apresentaram significância, indicando que nessa idade esses genotípos não sofrem influencias suficientes para diferenciar os teores de carboidratos totais na planta.

Os valores de CT encontrados neste trabalho são consistentes com os valores observados para a maioria das forrageiras tropicais. Lacerda et al. (2004), trabalhando com capim elefante sob corte em plantas com $1,8 \mathrm{~m}$ de altura, encontraram valores médios de $83,4 \%$.

Os carboidratos são importantes na nutrição de ruminantes, pois representam a principal fonte de energia para os microrganismos ruminais e para o animal (Mertens, 1994). Cerca de 70 a $90 \%$ dos carboidratos consumidos em sistemas extensivos são oriundos dos constituintes da parede celular (Lacerda et al., 2004). Estes valores dependem da idade de corte da forrageira, mas também do ambiente que também pode interferir nestes valores (Santos et al., 2001). Malafaia (1997) relata a importância da caracterização dos carboidratos ingeridos pelos ruminantes, face à utilização dessas informações, para a maximização do crescimento microbiano ruminal e, conseqüentemente, à melhor predição do desempenho dos animais, notadamente em condições tropicais.

Em relação aos teores dos CNF, semelhantes a algumas variáveis, apresentaram diferenças significativas $(p>0,05)$ entre os genotípos para lâminas foliares e colmos, com teores médios de 13,8 e 7,9\%, respectivamente. Campos et al. (2002), trabalhando com lâminas foliares e colmos de capim elefante, submetidas a corte com 65 dias, encontraram valores de 12,7 e $9,8 \%$ 


\section{RENDIMENTO E VALOR NUTRITIVO DE CLONES DE PENNISETUM SOB CORTE}

de CNF. Apesar dos teores de CNF serem considerados baixos, principalmente nos colmos, estes resultados estão dentro da amplitude descrita por Van Soest (1994) para gramíneas tropicais (2 e $10 \%$ do total de carboidratos). Os baixos teores de CNF deveram-se provavelmente ao aumento dos teores de FDN e lignina. $\mathrm{O}$ autor citado anteriormente, afirma em seu estudo a obtenção de um decréscimo nos teores de CNF com o avanço na maturidade das plantas, confirmando as citações de diversos autores (Deschamps et al., 2001; Campos et al., 2002), que afirmam que a lignificação tende a aumentar com a maturidade da planta.

Observou-se que, em lâminas foliares, apenas os teores de FDN $(0,84)$ e CT $(0,87)$ apresentaram alta herdabilidade. Em concordância com isso, observa-se que o coeficiente de variação (tabelas II e III) dessas variáveis foram bem reduzidos, indicando que as variações genéticas foram mais importantes que as variações ambientais. Já para as demais variáveis, o valor da herdabilidade entre os genotípos foi considerado médio, sem apresentarem significância, tendo variação de 0,35 até 0,64 (tabela II).

Os valores de herdabilidade em colmos foram altos para as variáveis $\mathrm{PB}(0,76)$, FDA $(0,79), \mathrm{MM}(0,70)$ e CNF $(0,75)$ e médios a baixos para $\mathrm{MS}(0,63), \operatorname{FDN}(0,51), \mathrm{EE}(0,54)$, CT $(0,68)$ e DIVMS $(0,25)$.

\section{BIBLIOGRAFIA}

Andrade, J.B, Ferrari Junior, E., Possenti, R.A., Otsuk, I.P., Zimback, L. e Landell, M.G.A. 2003. Produção e composição de genótipos de canade-açúcar. Bol. Indúst. Anim., 60: 11-22.

Barreto, G.P., Lira, M.A., Santos, M.V.F. e Dubeux Junior, J.C.B. 2001. Avaliação de clones de capim elefante (Pennisetum purpureum, Schum.) e de híbrido com o milheto (Pennisetum glaucum (L.)R.Br.) submetidos a estresse hídrico. Valor nutritivo. Rev. Bras. Zootecn. 30: 7 11.

Campos, F.P., Lanna, D.P.D., Bose, M.L.V., Boin, C. e Sarmento, P. 2002. Degradabilidade do
A variável FDN (lâminas foliares) e DIVMS (colmos) apresentaram baixa herdabilidade, o que provavelmente está associado a uma elevada variação ambiental. Assim, é de se esperar que a seleção para essas características não seja eficiente. Todavia, para melhorar esses caracteres, seria necessário aumentar a variação genética, pela introdução de novos materiais contrastantes na população.

Os resultados da herdabilidade entre os genótipos estudados sugerem que para selecionar características na composição nutricional, esta seleção deverá ser feita através da FDA e CT de lâminas foliares.

Considerando que as diferenças entre os tratamentos não foram evidentes, o aumento do número de tratamentos poderia contribuir para aumentar a herdabilidade e melhorar a precisão das estimativas.

\section{CONCLUSÃO}

Nas condições da zona da mata Norte de Pernambuco, os clones de Pennisteum avaliados foram similares quanto à produção de matéria seca e valor nutritivo, observando-se diferenças de valor nutritivo entre as lâminas foliares e colmos.

Os valores de herdabilidade indicam que os clones apresentaram variabilidade genética aos 60 dias de idade.

capim-elefante em diferentes estágios de maturidade avaliada pelo método in vitro/gás. Scientia Agric., 59: 217-225.

Carvalho, C.G.P., Arias, C.A.A., Toledo, J.F.F., Oliveira, M.F. e Vello, N.A. 2002. Correlações e análise de trilha em linhagens de soja semeadas em diferentes épocas. Pesqui. Agropecu. Bras., 37: 311-320.

Cruz, C.D. 2001. Programa Genes. Versão Windows: aplicativo computacional em genética e estatística. Universidade Federal de Viçosa. Viçosa. MG.

Deschamps, F.C. e Brito, C.J.F.A. 2001. Qualidade 


\section{SILVA, LIRA, SANTOS, DUBEUX JUNIOR, FREITAS E ARAÚJO}

da forragem e participação relativa na produção de matéria seca de diferentes frações de cultivares de capim elefante (Pennisetum purpureum Schumach.). Rev. Bras. Zootecn., 30: 1418-1423.

EMBRAPA. 1999. Empresa Brasileira de Pesquisa Agropecuária. Sistema brasileiro de classificação de solos. Embrapa Produção de Informação. Embrapa Solos, xxvi. Rio de Janeiro. Brasília. 412 pp.

Figueiredo, M.P., Sousa, S.A., Moreira, G.R., Sousa, L.F. e Ferreira, J.Q. 2004. Determinação do teor de matéria seca do capim elefante (Pennisetum purpureum, Schum.), em três estádios de maturidade fisiológica, pelo forno de microondas. Rev. Magistra. 16: 113-119.

Freitas, E.V., Lira, M.A., Dubeux Junior, J.C.B., Santos, M.V.F., Mello, A.C.L., Tabosa, J.N. e Farias, I. 2004. Características produtivas e qualitativas de clones de capim elefante (Pennisetum purpureum, Schum.) avaliados sob pastejo na Zona da Mata de Pernambuco. Acta Scient., 26: 251-257.

IPA. 1994. Banco de dados agrometereológicos. IPA. Recife. Brasil. 100 pp.

Kollet, J.L., Diogo, J.M.S. e Leite, G.G. 2006. Rendimento forrageiro e composição bromatológica de variedades de milheto (Pennisetum glaucum (L.) R. BR.). Rev. Bras. Zootecn., 35: 1308-1315.

Lacerda, P.D., Malafaia, P., Vieira, R.A.M., Henrique, D.S., Van Der Made, I.E. e Farta, A.R.G. 2004 Variação anual da composição bromatólogica de duas forrageiras cultivadas nas baixadas litorâneas do estado do Rio de Janeiro, Brasil. Ciência Rural, 34: 523-529.

Lira, M.A., Oliveira, T.N , Santos, M.V.F., Mello, A.C.L., Tavares, A.M.A., Dúbeux Júnior, J.C.B. e Moura, R.J.M. 2004. Herdabilidade de caracteres de clones Pennisetum sp. na Zona da Mata de Pernambuco. Em: Reunião Anual da SBZ, 41. Campo Grande. Anais. SBZ. Campo Grande.

Lira, M.A., Dubeux Junior, J.C.B., Oliveira, C.F. e Tabosa, J.N. 1999. Competição de cultivares de capim elefante (Pennisetum purpureum, Schum.) e de híbridos de capim-elefante $x$ milheto (Pennisetum americanum (L.) leeke) sob pastejo. Rev. Bras. Zootecn., 28: 936-946. Lopes, R.S., Fonseca, D.M., Oliveira, R.A.,
Andrade, A.C., Nascimento Junior, D. e Mascarenhas, A.G. 2005. Efeito da irrigação e adubação na disponibilidade e composição bromatólogica da massa seca de laminas foliares de capim elefante. Rev. Bras. Zootecn., 34: 20-29.

Malafaia, P.A.M. 1997. Determinação e cinética ruminal das frações protéicas de alguns alimentos para ruminantes. Rev. Bras. Zootecn., 26: 1243-1251.

Mello, A.C.L., Lira, M.A. e Dubeux Junior, J.C.B. 2006. Degradação ruminal da matéria seca de clones de capim elefante em função da relação folha/colmo. Rev. Bras. Zootecn., 35: 13161322.

Mello, A.C.L., Melo, V.T., Santos, M.V.F., Lira, M. A., Cunha, M.V. e Oliveira, T.N. 2006a. Herdabilidade de caracteres morfológicos em genótipos de Pennisetum sp. Avaliados na fase de maturidade. Em: IV Congresso Nordestino de Produção Animal, Petrolina. Anais. SNPA. Petrolina.

Mello, A.C.L., Lira, M.A., Dubeux Junior, J.C.B., Santos, M.V.F. e Freitas, E.V. 2002. Caracterização e seleção de clones de capim-elefante (Pennisetum purpureum, Schum.) na Zona da Mata de Pernambuco. Rev. Bras. Zootecn., 31: 30-42.

Mertens, D.R. 1994. Regulation of forage intake. In: FAHEY JR., G.C. (Ed.). Forage quality, evaluation and utilization. American Society of Agronomy. Winsconsin. pp. 450-493.

Missio, R.L., Brondani, I.L., Menezes, L.F.G., Arboitte, M.Z., Alves Filho, D.C., Restler, J., Leite, D.T. e Pizzutti, L.A.D. 2006. Massas de lâminas foliares nas características produtivas e qualitativas da pastagem de capim elefante (Pennisetum purpureum, Schum. Cv. Taiwan) e desempenho animal. Ciência Rural, 36: 12431248.

Minson, D.J.1984. Effects of chemical and physical composition of herbaje eaten upon intake. In: Hacker, J.B. (Ed.). Nutritional limits to animal production from pasture. CAB. Farnham Royal. pp. 167-182.

Nussio, L.G., Campos, F.P. e Lima, M.L.M. 2006. Metabolismo de carboidratos. Em: Nutrição de ruminantes. Bertielli, T.T., Pires, A.V., Oliveira, S.G. Editora FUNEP. Jaboticabal. pp. 183-223. $583 \mathrm{pp}$.

Archivos de zootecnia vol. 60, núm. 229, p. 72. 


\section{RENDIMENTO E VALOR NUTRITIVO DE CLONES DE PENNISETUM SOB CORTE}

Nussio, L.G., Manzano, R.P. e Pedreira, C.G.S 1998. Valor alimentício em plantas do gênero Cynodon. Em: Simpósio Sobre Manejo da Pastagem, Piracicaba. Anais. Fundação de Estudos Agrários "Luiz de Queiroz". Piracicaba. pp. 203-242.

Oliveira, T.N, Santos, M.V.F., Lira, M.A., Mello, A.C.L., Ferreira, R.L.C. e Dubeux Junior, J.C.B. 2007. Métodos de avaliação de disponibilidade de forragem em clones de Pennisetum sp. sob pastejo. Rev. Bras. Ciencias Ágrarias, 2: 168173.

Oliveira, C.F. 1999. Avaliação sob pastejo de clones de capim elefante (Pennisetum purpureum, Schum.) e de seus híbridos com milheto (Pennisetum americanum (L.) Leeke) na Zona da Mata de Pernambuco: Recife, PE. Dissertação (Mestrado em Produção Animal). Universidade Federal Rural de Pernambuco. $111 \mathrm{pp}$.

Pereira, A.V., Ferreira, R.P., Passos, L.P., Freitas, V.P., Verneque, R.S., Barra, R.B. e Silva, C.H.P 2000. Variação da qualidade de folhas em cultivares de capim-elefante (Pennisetum purpureum) e híbridos de capim-elefante x milheto ( $P$. purpureum $\times P$. glaucum), em função da idade da planta. Rev. Ciência Agrotecnol., 24: 490-499.

Pinto, J.C., Chaves, C.A.S., Perez, J.R.O., Oliveira, A.I.G. e Rocha, G.P. 1999. Valor nutritivo das silagens de capim-sudão, milheto, teosinto e milho. 1 - consumo e digestibilidade aparente 1 . Rev. Ciência Agrotecnol., 23: 980-986.

Pompeu, R.C.F.F., Neiva, J.N.M., Candido, M.J.D., Oliveira Filho, G.S., Aquino, D.C. e Lobo, R.N.B. 2006. Valor nutritivo de silagens de capim elefante (Pennisetum purpureum, Schum.) com adição de subprodutos do processamento de frutas tropicais. Rev. Ciência Agron., 37: 7783.

Queiroz Filho, Silva, D.S. e Nascimento, I.S. 2000 Produção de matéria seca e qualidade do Capim elefante (Pennisetum purpureum, Schum) cultivar roxo em diferentes idades de corte. Rev. Bras. Zootecn., 29: 69-74.

Reis, J., Paiva, P.C.A., Tiesenhausen, I.M.E.Y. e Resende, C.A.P. 2000. Composição química, consumo voluntário e digestibilidade de silagens de resíduos do fruto de maracujá (Passiflora edulis Sims f. flavicarpa) e de capim-elefante
(Pennisetum purpureum, Schum.) cv. cameroon e suas combinações 1. Rev. Ciência Agrotecnol., 24: 213-224.

Rodrigues, A.L.P , Sampaio, I.B.M , Carneiro, J.C., Tomich, T.R. and Martins, R.G.R. 2004. Degradabilidade in situ da matéria seca de forrageiras tropicais obtidas em diferentes épocas de corte. Arq. Bras. Med. Veter. Zootecn., 56: 658-664.

Santos, E.A., Silva, D.S. e Queiroz Filho, J.L. 2001 Composição química do capim elefante cv. roxo cortado em diferentes alturas. Rev. Bras. Zootecn., 30: 18-23.

Santos, M.V.F., Nascimento Junior, D., Pereira, J., Regazzi, A.J., Silva, A.G. e Diogo, J.M.S. 1998. Composição florística, densidade e altura de uma pastagem natural sob Pastejo. Rev. Bras. Zootecn., 27: 1082-1091.

Santos, M.C.S., Tabosa, J.N., Dias, F.M., Freitas, E.V. e Lira, M.A. 1994. Comportamento de clones de capim elefante e de híbridos de capim elefante $\mathrm{x}$ milheto no semi-árido do Nordeste do Brasil. Pesqui. Agropecu. Bras., 29: 1609-1615.

Shimoya, A., Pereira, A.V., Reinaldo, P.F., Cruz, C.D. e Carneiro, P.C.S. 2002. Repetibilidade de características forrageiras do capim elefante. Scientia Agríc., 59: 227-234.

Silva, D.J. e Queiroz, A.C. 2002. Análise de Alimentos: métodos químicos e biológicos. UFV. Viçosa. $235 \mathrm{pp}$.

Silva, M.M.P., Vasquez, H.M. e Silva, J.F.C. 2002. Composição bromatológica, disponibilidade de forragem e índice de área foliar de 17 genótipos de capim elefante (Pennisetum purpureum, Schum.) sob pastejo, em Campos dos Goytacazes, RJ. Rev. Bras. Zootecn., 31: 313320

Silva, A.L.C. 2001. Avaliação e seleção de clones de capim elefante (Pennisetum purpureum, Schum.) na Zona da Mata de Pernambuco. Dissertação (Mestrado em Zootecnia). Universidade Federal Rural de Pernambuco. Pernambuco, PE. 83 pp.

Sniffen. C.J., O' Connor, J.D., Van Soest, P.J., Fox, D.G. and Russell, J.B. 1992. A net carbohydrate and protein system for evaluating cattle diets: II. Carbohydrate and protein availability. J. Anim. Sci., 70: 3562-3577.

Soares, J.P.G., Berchielli, T.T., Aroeira, L.J.M., Deresz, F. e Verneque, R.S. 2004. Estimativas 


\section{SILVA, LIRA, SANTOS, DUBEUX JUNIOR, FREITAS E ARAÚJO}

de consumo do capim elefante (Pennisetum purpureum, Schum.), fornecido picado para vacas lactantes utilizando a técnica do óxido crômico. Rev. Bras. Zootecn., 33: 811-820.

Sobrinho, F.S., Pereira, A.V., Ledo, F.J.S., Botrel, M.A., Oliveira, J.S. e Xavier, D.F. 2005. Avaliação agronômica de híbridos interespecíficos entre capim-elefante e milheto. Pesqui. Agropecu. Bras., 40: 873-880

Tilley, J.M. and Terry, R.A. 1963. A two stage technique for the in vitro digestion of forages crops. J. Brit. Grassl. Soc., 18: 104-111.

Valadares Filho, S.C., Broderick, G.A., Valadares, R.F.D. e Clayton, M.K. 2000. Effect of replacing alfalfa silage with high moisture corn on nutrient utilization and milk production. J. Dairy Sci., 83:
106-114.

Valle, C.B. do. e Souza, F.H.D. 1995. Construindo novos cultivares de gramíneas forrageiras para os cerrados brasileiros. Em: Reunião Anual da Sociedade Brasileira de Zootecnia, 32. Anais. SBZ. Brasília. pp. 3-7.

Van Soest, P.J. 1965. Symposium on factors influencing the voluntary intake of herbage by ruminants: voluntary intake relation to chemical composition and digestibility. J. Anim. Sci., 24: 834-844.

Van Soest, P.J. 1994. Nutritional ecology of the ruminant. Cornell University. Ithaca. $476 \mathrm{pp}$.

Verité, R. et Journet, M. 1970. Facteurs quis limitent prise de vaches de la laiterie. Ann. Zootech., 19: 265-278.

Archivos de zootecnia vol. 60, núm. 229, p. 74. 